\title{
Reliable Method for Steady-State Concentrations and Current over the Diagnostic Biosensor Transducers
}

\author{
Kurunatha Perumal Thevar Preethi ${ }^{1 *}$, Velmurgan Meena², Rajaram Poovazhaki ${ }^{*}$ \\ ${ }^{1}$ Department of Mathematics, E.M.G. Yadava Women's College, Madurai, India \\ ${ }^{2}$ Department of Mathematics, Madurai Kamaraj University Constitutional College, Madurai, India \\ Email: ^rain.preethi90@gmail.com, meenakvishwa@gmail.com, ^rpoovazhaki@yahoo.co.in
}

How to cite this paper: Preethi, K.P.T., Meena, V. and Poovazhaki, R. (2017) Reliable Method for Steady-State Concentrations and Current over the Diagnostic Biosensor Transducers. American Journal of Analytical Chemistry, 8, 493-513. https://doi.org/10.4236/ajac.2017.87036

Received: April 19, 2017

Accepted: July 9, 2017

Published: July 12, 2017

Copyright $\odot 2017$ by authors and Scientific Research Publishing Inc. This work is licensed under the Creative Commons Attribution International License (CC BY 4.0). http://creativecommons.org/licenses/by/4.0/

\begin{abstract}
A mathematical modelling of diagnostic biosensors system at three basic types of enzyme kinetics is discussed in the presence of diffusion. Enzyme kinetics is adopted to be first order, Michaelis-Menten and ping-pong mechanism. In this paper, approximate analytical solutions are obtained for the non-linear equations under steady-state conditions by using the new Homotopy perturbation method. Simple and closed forms of analytical expressions for concentrations of substrate, product and co-substrate and corresponding current response have been derived for all possible values of parameters. Furthermore, the numerical simulation of the problem is also reported here by using Matlab program. Good agreement between analytical and numerical results is noted.
\end{abstract}

\section{Keywords}

Diagnostic Biosensor, Bio Fuel, Enzyme, Kinetic, Non Linear Equations, Reaction/Diffusion Equation, Homotopy Perturbation Method

\section{Introduction}

A biosensor is an analytical device used for the detection of an analyte that combines a biological component with a physicochemical detector [1] [2]. The earlier biosensors were catalytic systems that integrated especially enzymes with transducers that converted the biological response into an electronic signal. The next generation of biosensors, took advantage of different biological elements, such as antibodies, receptors (natural or synthetic), or nucleic acids [3] [4].

Biosensors for environmental application include the detection of harmful bacteria or pesticides in air, water, or food. New technologies are likely to encompass all-printed systems capitalising on the printed electronics revolution 
and systems with high compatibility with future mobile technology such as tablets and $4 \mathrm{G}$ phones [5].

Rangelova et al. [6] [7] [8] described the models in biosensors and investigated the influence of the diffusion and kinetic parameters on the response of the biosensor. Tothil et al., [9] deals with the recent developments in biosensors and their potential use in the agricultural diagnostic market. Mishra et al. [10] reviewed various cancer biomarkers in saliva and compared the biomarkers efficacy with traditional diagnostics and state-of-the-art bioelectronics. Cortina et al. [11] presented the development and validation of a portable, robust and inexpensive electrochemical magnetic biosensor.

Lawal et al. [12] summarized the fabrication of carbon nanotubes-based electrochemical biosensors. They also discussed the synthesis, along with the application of carbon nanotubes to the assembly of carbon nanotube-based electrochemical sensors, its analytical performance and future expectations. Recently Gruhl et al. [13] described the latest applications of biosensors in diagnostic applications. In this paper the current state and future trends of biosensors are presented. Also Mascini et al. [3] reviewed the application of biosensor sin medical diagnostics, taking into account several crucial features.

The numerical method of solving the system of partial differential equations is to make calculation at all intervals of substrates concentration and at different diffusion and enzymatic reaction rates. The diffusion equations [14], containing a nonlinear term related to the enzymatic reaction, are carried out using the implicit difference scheme [15]. In recent years, analytical solutions are reported for various types of biosensors [16] [17] [18] [19]. The analytical results of diagnostic biosensor are relevant because their solutions describe important applications such as bioreactors and biofuel cells, among others [20] [21].

To the researcher's knowledge no rigorous analytical solution of substrate concentration product with concentration profiles co-substrate concentration and corresponding current response has been derived for all possible values of parameters under steady-state conditions [22]. The purpose of this communication is to derive approximate analytical expressions for the steady-state concentrations and current over the diagnostic of biosensor transducers for first order, Michaelis-Menten and ping-pong kinetics using Homotopy perturbation method.

\section{Mathematical Description of the Boundary Value Problem}

Only biosensors systems will be investigated in the active membrane, because it is known that the concentrations of substrate $S(x)$, Product $P(x)$ and co-substrate $C(x)$ in other two membranes are changed linearly. Biosensors are function under diffusion control. It is assumed that the electrode has symmetrical geometry and the enzyme is homogeneously distributed in the active membrane. The diffusion is one dimensional in space and is described with the second Fick's law. The two parameters diagnostic biosensor transducers are based on oxygen electrode. The steady-state reaction-diffusion equation for bio- 
sensor systems in the dynamic mode has the following form [22]:

$$
\frac{\mathrm{d}^{2} S}{\mathrm{~d} x^{2}}-\vartheta(S, C)=0, \frac{1}{\lambda} \frac{\mathrm{d}^{2} P}{\mathrm{~d} x^{2}}-\vartheta(S, C)=0, \frac{1}{\mu \rho} \frac{\mathrm{d}^{2} C}{\mathrm{~d} x^{2}}-\vartheta(S, C)=0
$$

The non-dimensional coordinates, variables and parameters are as follows:

$$
\begin{aligned}
& x=\frac{\delta}{l}, S=\frac{[S]}{K_{S}}, C=\frac{[C]}{K_{C}}, P=\frac{[P]}{K_{P}}, S_{o}=\frac{[S]}{K_{S}}, \\
& \lambda=\frac{D_{S}}{D_{P}}, \mu=\frac{D_{S}}{D_{C}}, \rho=\frac{K_{S}}{K_{C}} \text { and } \phi=\frac{\left(V_{m} / K_{S}\right)}{\left(I^{2} / D_{S}\right)}
\end{aligned}
$$

where $D_{S}, D_{C} \& D_{P}$ are diffusion coefficients for substrate, co-substrate and product. $K_{i}$ denotes the reaction constant for concentration profiles ( $i=S, P, C$ ), respectively. $V_{m}$ is the enzyme rate and $\delta$ represents the coordinate distance. The diagnosis of the biosensor system depends on the enzyme kinetics and the enzyme reaction as well as on the basic transducer. The kinetics is distinguished in to three kinds:

First order kinetic:

$$
\vartheta(S, C)=\phi^{2} S
$$

Michaelis-Menten kinetic:

$$
\vartheta(S, C)=\frac{\phi^{2} S}{1+S}
$$

Two substrateping-pong kinetic:

\begin{tabular}{|c|c|c|c|}
\hline Inhibitor & First-order kinetic & Michaelis-Menten kinetic & Ping-pong kinetic \\
\hline Substrate & $\frac{\mathrm{d}^{2} S}{\mathrm{~d} x^{2}}-\phi^{2} S=0$ & $\frac{\mathrm{d}^{2} S}{\mathrm{~d} x^{2}}-\frac{\phi^{2} S}{1+S}=0$ & $\frac{\mathrm{d}^{2} S}{\mathrm{~d} x^{2}}-\frac{\phi^{2}}{1+1 / S+1 / C}=0$ \\
\hline Product & $\frac{1}{\lambda} \frac{\mathrm{d}^{2} P}{\mathrm{~d} x^{2}}+\frac{\phi^{2} S}{1+S}=0$ & $\frac{1}{\lambda} \frac{\mathrm{d}^{2} P}{\mathrm{~d} x^{2}}+\frac{\phi^{2} S}{1+S}=0$ & $\frac{1}{\lambda} \frac{\mathrm{d}^{2} P}{\mathrm{~d} x^{2}}+\frac{\phi^{2}}{1+1 / S+1 / C}=0$ \\
\hline $\begin{array}{c}\text { Co } \\
\text { Substrate }\end{array}$ & $\frac{1}{\mu \rho} \frac{\mathrm{d}^{2} C}{\mathrm{~d} x^{2}}-\phi^{2} S=0$ & $\frac{1}{\mu \rho} \frac{\mathrm{d}^{2} C}{\mathrm{~d} x^{2}}-\frac{\phi^{2} S}{1+S}=0$ & $\frac{1}{\mu \rho} \frac{\mathrm{d}^{2} C}{\mathrm{~d} x^{2}}-\frac{\phi^{2}}{1+1 / S+1 / C}=0$ \\
\hline
\end{tabular}

$$
\vartheta(S, C)=\frac{\phi^{2} S}{1+\frac{1}{S}+\frac{1}{C}}
$$

The three types of biosensors can be described with the following system of differential equations:

Equations (5)-(13) are subjected to the following boundary conditions:

$$
\begin{gathered}
x=0, S(x)=s_{0}, P(x)=0, C(x)=c_{0} \\
x=1, \frac{\mathrm{d} S}{\mathrm{~d} x}=0, P(x)=0, C(x)=0
\end{gathered}
$$

where $l$ represents the thickness of active membrane, $\phi^{2}$ is the Thiele Module, $\lambda$ is diffusion coefficient of product, $\mu$ is the diffusion coefficient of 
co-substrate and $\rho$ is reaction rate constant for co-substrate. The initial current of the biosensor system is recorded normally in substrate, product and co-substrate concentrations at the electrode and are as follows:

$$
\begin{aligned}
I_{S} & =n F A D_{S}\left(\frac{\mathrm{d} S}{\mathrm{~d} \delta}\right)_{\delta=0} \\
I_{P} & =n F A D_{P}\left(\frac{\mathrm{d} P}{\mathrm{~d} \delta}\right)_{\delta=0} \\
I_{C} & =n F A D_{C}\left(\frac{\mathrm{d} C}{\mathrm{~d} \delta}\right)_{\delta=0}
\end{aligned}
$$

where $n$ is the number of electrons taking part in electrochemical reaction, $F$ is the Faraday's number, and $A$ is the area of the electrode surface $\left[\mathrm{m}^{2}\right]$.

\section{Analytical Solutions of Concentrations of Substrate, Product and Co-Substrate under Steady-State Condition Using the New Homotopy Perturbation Method}

Recently, many authors have applied the HPM to solve the various non-linear problem in engineering sciences [23]-[28]. This method is a combination of Homotopy in topology and classic perturbation techniques. The HPM has uniqueness in its applicability, accuracy, and efficiency. Recently, a new approach of HPM with zeroth iteration has been applied to solve the nonlinear problem. In this work, a new approach to Homotopy perturbation method is used (Appendix A and Appendix B) to solve the nonlinear differential Equations (5)-(13). Using this method, the analytical expression of the concentration of substrate $S(x)$, Product $P(x)$ and co-substrate $C(x)$ can be obtained as follows:

The first order kinetic Equations (18)-(20) represent the simple and closed form of analytical expressions of concentrations of substrate, product and cosubstrate for all possible values of the parameters. By using Equations (5)-(7)

\begin{tabular}{|c|c|c|c|c|}
\hline Inhibitors & Analytical solutions & Figures & Current Solutions & Figures \\
\hline Substrate & $S(x)=S_{0}+A_{1}\left(\frac{x^{2}}{2}-x\right)$ & 1(a) & $\psi_{S_{1}}=\frac{I_{S} l}{n F A D_{s}}=-A_{1}$ & - \\
\hline Product & $P(x)=\frac{-\lambda A_{1}}{2}\left(x^{2}-x\right)$ & $\begin{array}{l}1(\mathrm{~b}) \\
\text { and } \\
1(\mathrm{c})\end{array}$ & $\psi_{P_{1}}=\frac{I_{P} l}{n F A D_{P}}=A_{1} \frac{\lambda}{2}$ & 6(a) \\
\hline $\begin{array}{c}\text { Co } \\
\text { substrate }\end{array}$ & $C(x)=\frac{\mu \rho A_{1}}{2}\left(x^{2}-x\right)+C_{0}(1-x)$ & $\begin{array}{l}1(\mathrm{~d}) \\
\text { and } \\
1(\mathrm{f})\end{array}$ & $\psi_{C_{1}}=\frac{I_{C} l}{n F A D_{C}}=-\left(A_{1} \frac{\mu \rho}{2}+c_{0}\right)$ & $\begin{array}{l}7(\mathrm{a}) \\
\text { and } \\
7(\mathrm{~b})\end{array}$ \\
\hline
\end{tabular}
with boundary conditions (14), the following relation is also obtained:

First order kinetic

The Michaelis-Menten kinetic Equations (24)-(26) represent the simple and closed form of analytical expressions of concentrations of substrate, product and co-substrate for all possible values of the parameters. By using Equations (8)-(10) with boundary conditions (14), the following relation is also obtained: 
Michaelis-Menten kinetic:

\begin{tabular}{|c|c|c|c|c|}
\hline Inhibitors & Analytical solutions & Figures & Current solutions & Figures \\
\hline Substrate & $S(x)=s_{0}+A_{2}\left(\frac{x^{2}}{2}-x\right)$ & 2(a) & $\psi_{S_{2}}=\frac{I_{s} l}{n F A D_{s}}=-A_{2}$ & - \\
\hline Product & $P(x)=\frac{-\lambda A_{2}}{2}\left(x^{2}-x\right)$ & $\begin{array}{l}2(\mathrm{~b}) \\
\text { and } \\
2(\mathrm{c})\end{array}$ & $\psi_{P_{2}}=\frac{I_{p} l}{n F A D_{P}}=A_{2} \frac{\lambda}{2}$ & $6(b)$ \\
\hline Co substrate & $C(x)=\frac{\mu \rho A_{2}}{2}\left(x^{2}-x\right)+c_{0}(1-x)$ & $\begin{array}{l}2(d) \\
\text { and } \\
2(f)\end{array}$ & $\begin{array}{c}\psi_{C_{2}}=\frac{I_{C} l}{n F A D_{C}}=-\left(A_{2} \frac{\mu \rho}{2}+C_{0}\right) \\
(29)\end{array}$ & $\begin{array}{l}7(\mathrm{c}) \\
\text { and } \\
7(\mathrm{~d})\end{array}$ \\
\hline
\end{tabular}

The Ping pong kinetic: Equations (30)-(32) represent the simple and closed forms of analytical expressions of concentrations of substrate, product and cosubstrate for all possible values of the parameters. By using Equations (11)-(13) with boundary conditions (14), the following relation is also obtained:

Ping pong kinetic:

\begin{tabular}{|c|c|c|c|c|}
\hline Inhibitors & Analytical solutions & Figures & Current solutions & Figures \\
\hline Substrate & $S(x)=S_{0}+A_{3}\left(\frac{x^{2}}{2}-x\right)$ & $3(\mathrm{a})$ & $\psi_{S_{3}}=\frac{I_{s} l}{n F A D_{s}}=-A_{3}$ & - \\
\hline Product & $P(x)=\frac{-\lambda A_{3}}{2}\left(x^{2}-x\right)$ & $\begin{array}{c}3(b) \\
\text { and } 3(c)\end{array}$ & $\psi_{P_{3}}=\frac{I_{p} l}{n F A D_{P}}=A_{3} \frac{\lambda}{2}$ & $6(c)$ \\
\hline $\begin{array}{c}\text { Co } \\
\text { substrate }\end{array}$ & $C(x)=\frac{\mu \rho A_{3}}{2}\left(x^{2}-x\right)+c_{0}(1-x)$ & $3(\mathrm{~d})-(\mathrm{f})$ & $\psi_{C_{3}}=\frac{I_{C} l}{n F A D_{C}}=-\left(A_{3} d \frac{\mu \rho}{2}+c_{0}\right)$ & $\begin{array}{l}7(\mathrm{e}) \\
\text { and } \\
7(\mathrm{f})\end{array}$ \\
\hline
\end{tabular}

where $A_{1}=\phi^{2} s_{0}, \quad A_{2}=\frac{\phi^{2} s_{0}}{1+s_{0}}$ and $A_{3}=\frac{\phi^{2}}{1+\left(1 / s_{0}\right)+\left(1 / c_{0}\right)}$.

\section{Numerical Simulation}

The system of non-linear differential Equations (5)-(13) with boundary conditions (14) have been solved numerically using MATLAB software. A MATLAB script pdex4 is provided in Appendix C. In Figure 4, Tables 1-3 the numerical solutions are compared with the analytical results. The maximum average relative error between our analytical and numerical result is $0.94 \%$ for first order kinetic, $0.91 \%$ for Michaelis-Menten kinetic and $1.54 \%$ for Ping pong kinetic.

\section{Results and Discussion}

The dinensonless non-linear differential equations are solved using a new Homotopy perturbation method. Equations (18)-(20), (24)-(26) and (30)-(32) represent the analytical expression of the concentrations of substrate, product and co-substrate for various values of Thiele modulus $\phi^{2}$ and the dimensionless parameters for first order, Michalies-Menten and Ping-Pong kinetics respectively. The analytical results are compared with the numerical results. 
Table 1. Comparison of dimensionless concentrations $S(x), P(x)$ and $C(x)$ (Equations (18)-(20)) and numerical simulation for first order kinetics when fixed value of $\phi^{2}=0.3, \lambda=10, \mu=1$ and $\rho=1$.

\begin{tabular}{|c|c|c|c|c|c|c|c|c|c|}
\hline \multicolumn{4}{|c|}{ Substrate } & \multicolumn{3}{|c|}{ Product } & \multicolumn{3}{|c|}{ Co-substrate } \\
\hline$x$ & $\begin{array}{c}\text { This } \\
\text { Work } \\
\text { Equation } \\
(18)\end{array}$ & $\begin{array}{c}\text { Numerical } \\
\text { soln }\end{array}$ & $\begin{array}{l}\% \text { of } \\
\text { Error }\end{array}$ & $\begin{array}{c}\text { This } \\
\text { Work } \\
\text { Equation } \\
\text { (19) }\end{array}$ & $\begin{array}{c}\text { Numerical } \\
\text { soln }\end{array}$ & $\begin{array}{l}\% \text { of } \\
\text { Error }\end{array}$ & $\begin{array}{c}\text { This } \\
\text { Work } \\
\text { Equation } \\
\text { (20) }\end{array}$ & $\begin{array}{c}\text { Numerical } \\
\text { soln }\end{array}$ & $\begin{array}{l}\% \text { of } \\
\text { Error }\end{array}$ \\
\hline 0.0 & 1.0000 & 1.0000 & 0.00 & 0.0000 & 0.0000 & 0.00 & 1.0000 & 1.0000 & 0.00 \\
\hline 0.2 & 0.9512 & 0.9530 & 0.18 & 0.2400 & 0.2383 & 0.17 & 0.7760 & 0.7748 & 0.15 \\
\hline 0.4 & 0.9139 & 0.9133 & 0.06 & 0.3600 & 0.3685 & 0.23 & 0.5640 & 0.5631 & 0.15 \\
\hline 0.6 & 0.8875 & 0.8859 & 0.19 & 0.3600 & 0.3565 & 0.98 & 0.3640 & 0.3617 & 0.63 \\
\hline 0.8 & 0.8719 & 0.8715 & 0.04 & 0.2400 & 0.2419 & 0.78 & 0.1760 & 0.1751 & 0.51 \\
\hline 1.0 & 0.8667 & 0.8667 & 0.00 & 0.0000 & 0.0000 & 0.00 & 0.0000 & 0.0000 & 0.00 \\
\hline \multicolumn{3}{|c|}{ Average $\%$ error } & 0.94 & \multicolumn{2}{|c|}{ Average \% error } & 0.43 & \multicolumn{2}{|c|}{ Average \% error } & 0.29 \\
\hline
\end{tabular}

Table 2. Comparison of dimensionless concentrations $S(x), P(x)$ and $C(x)$ (Equation (24)-(26)) and numerical simulation for Michaelis-Menten kinetics when fixed value of $\phi^{2}=0.3, \lambda=50, \mu=1$ and $\rho=1$.

\begin{tabular}{|c|c|c|c|c|c|c|c|c|c|}
\hline \multicolumn{4}{|c|}{ Substrate } & \multicolumn{3}{|c|}{ Product } & \multicolumn{3}{|c|}{ Co-substrate } \\
\hline$x$ & $\begin{array}{c}\text { This } \\
\text { Work } \\
\text { Equation } \\
(24)\end{array}$ & $\begin{array}{c}\text { Numerical } \\
\text { soln }\end{array}$ & $\begin{array}{l}\% \text { of } \\
\text { Error }\end{array}$ & $\begin{array}{c}\text { This } \\
\text { Work } \\
\text { Equation } \\
\text { (25) }\end{array}$ & $\begin{array}{c}\text { Numerical } \\
\text { soln }\end{array}$ & $\begin{array}{l}\% \text { of } \\
\text { Error }\end{array}$ & $\begin{array}{c}\text { This } \\
\text { Work } \\
\text { Equation } \\
\text { (26) }\end{array}$ & $\begin{array}{c}\text { Numerical } \\
\text { soln }\end{array}$ & $\begin{array}{l}\% \text { of } \\
\text { Error }\end{array}$ \\
\hline 0.0 & 0.0000 & 0.0000 & 0.00 & 0.0000 & 0.0000 & 0.00 & 1.0000 & 1.0000 & 0.00 \\
\hline 0.2 & 0.9730 & 0.9700 & 0.30 & 0.600 & 0.5911 & 1.50 & 0.7880 & 0.7967 & 1.09 \\
\hline 0.4 & 0.9520 & 0.9513 & 0.07 & 0.900 & 0.8999 & 0.01 & 0.5820 & 0.5886 & 1.12 \\
\hline 0.6 & 0.9370 & 0.9380 & 0.10 & 0.900 & 0.8997 & 0.03 & 0.3820 & 0.3865 & 1.16 \\
\hline 0.8 & 0.9280 & 0.9300 & 0.21 & 0.600 & 0.6081 & 1.33 & 0.1880 & 0.1903 & 1.20 \\
\hline 1.0 & 0.9250 & 0.9273 & 0.24 & 0.0000 & 0.0000 & 0.00 & 0.0000 & 0.0000 & 0.00 \\
\hline \multicolumn{3}{|c|}{ Average \% error } & 0.18 & \multicolumn{2}{|c|}{ Average $\%$ error } & 0.58 & \multicolumn{2}{|c|}{ Average $\%$ error } & 0.91 \\
\hline
\end{tabular}

Table 3. Comparison of dimensionless concentrations $S(x), P(x)$ and $C(x)$ (Equations (30)-(32)) and numerical simulation for ping pong kinetics when fixed value of $\phi^{2}=0.1, \lambda=10, \mu=10$ and $\rho=1$.

\begin{tabular}{|c|c|c|c|c|c|c|c|c|c|}
\hline \multicolumn{4}{|c|}{ Substrate } & \multicolumn{3}{|c|}{ Product } & \multicolumn{3}{|c|}{ Co-substrate } \\
\hline$x$ & $\begin{array}{c}\text { This } \\
\text { Work } \\
\text { Equation } \\
\text { (30) }\end{array}$ & $\begin{array}{c}\text { Numerical } \\
\text { soln }\end{array}$ & $\begin{array}{l}\% \text { of } \\
\text { Error }\end{array}$ & $\begin{array}{c}\text { This } \\
\text { Work } \\
\text { Equation } \\
\text { (31) }\end{array}$ & $\begin{array}{l}\text { Numerical } \\
\text { soln }\end{array}$ & $\begin{array}{l}\% \text { of } \\
\text { Error }\end{array}$ & $\begin{array}{c}\text { This } \\
\text { Work } \\
\text { Equation } \\
\quad(32)\end{array}$ & $\begin{array}{c}\text { Numerical } \\
\text { soln }\end{array}$ & $\begin{array}{l}\% \text { of } \\
\text { Error }\end{array}$ \\
\hline 0.0 & 1.0000 & 1.0000 & 0.00 & 0.0000 & 0.0000 & 0.00 & 1.0000 & 1.0000 & 0.00 \\
\hline 0.2 & 0.9940 & 0.9965 & 0.25 & 0.0266 & 0.0213 & 0.66 & 0.7733 & 0.7799 & 0.84 \\
\hline 0.4 & 0.9893 & 0.9937 & 0.44 & 0.0400 & 0.0389 & 2.82 & 0.5600 & 0.5676 & 1.33 \\
\hline 0.6 & 0.9860 & 0.9922 & 0.62 & 0.0399 & 0.0393 & 1.52 & 0.3600 & 0.3673 & 1.98 \\
\hline 0.8 & 0.9840 & 0.9916 & 0.76 & 0.0266 & 0.0259 & 2.70 & 0.1733 & 0.1760 & 1.53 \\
\hline 1.0 & 0.9833 & 0.9899 & 0.12 & 0.0000 & 0.0000 & 0.00 & 0.0000 & 0.0000 & 0.00 \\
\hline \multicolumn{3}{|c|}{ Average $\%$ error } & 0.44 & \multicolumn{2}{|c|}{ Average $\%$ error } & 1.54 & \multicolumn{2}{|c|}{ Average \% error } & 1.14 \\
\hline
\end{tabular}


Figures 1-3 show the plots of all the concentrations versus dimensionless distance $x$ for various values of parameters. For $\phi^{2}>1$, biosensors act in diffusion regime, and for $\phi^{2}<1$, the biosensors act in rule of limiting kinetic. Reaction rate constant for substrate $K_{S}$ is dependable from enzyme concentration and characterized enzyme. There are different enzymes for various tissues, where as reaction rate constant is permanent for the given tissue. The strong affinity between enzyme and substrate shows low value of kinetics and poor affinity shows high value.

The substrate concentration $S(x)$ approaches unity at $x=0$. The substrate concentration increases with decreasing Thiele module. When the ratio of diffusion coefficient $\lambda$ increases, the Thiele module increases the product. The concentration of co-substrate increases, when Thiele module decreases. If the ratio of diffusion coefficient $\mu$ and ratio of reaction rate constant $\rho$ increases, the concentration of co-substrate decreases.

Figure 4 focuses the concentration on the first-order kinetics, MichaelisMenten kinetics, and ping-pong kinetic mechanism of the substrate $S(x)$, product $P(x)$ and co-substrate $C(x)$ for particular values of parameters. The analytical results are compared with the numerical results as given in Tables 1-3 for fixed values of parameters and satisfactory agreement is noted. In all the cases, the average relative error is less than $1.54 \%$.

Figure 5 represents the concentration of the substrate, product and co-substrate vursus distance for the first-order kinetics, Michaelis-Menten kinetics, and ping-pong kinetic mechanism for particular values of parameters. From this figure, it is inferred that the concentration of the ping-pong kinetics largely corresponds to the other two mechanisms. But for the co substrate, the concentration does not show much difference. From these Figure, it is concluded that the dimensionless concentration of substrate and co-substrateis greater for the Ping-Pong than the first order and M-M kinetics.

Figure 6 and Figure 7 represent the dimensionless current profiles of product and co-substrate for various values of dimensionless parameters. The current depends on the product and co-substrate gradient at the electrode surface. $D_{S}$ has no influenced over biosensor response, but $D_{C}$ and $D_{P}$ has been increasing the value of the diffusion constant $D_{C}$ and $D_{P}$ leads to small values of response time.

\section{Conclusion}

In this work, a mathematical model that describes the steady-state response of a two parameters diagnostic of biosensor is discussed. Anew Homotopy perturbation method is employed to solve the system of steady-state non-linear differential equations for three types of kinetics. Analytical expressions corresponding to substrate, product and co-substrate concentrations are derived as the function of dimensionless parameters. For all different concentrations, the analytical results match well with the simulated results. The analytical results provided in this work are useful to understand the behaviour of the system. The extension 


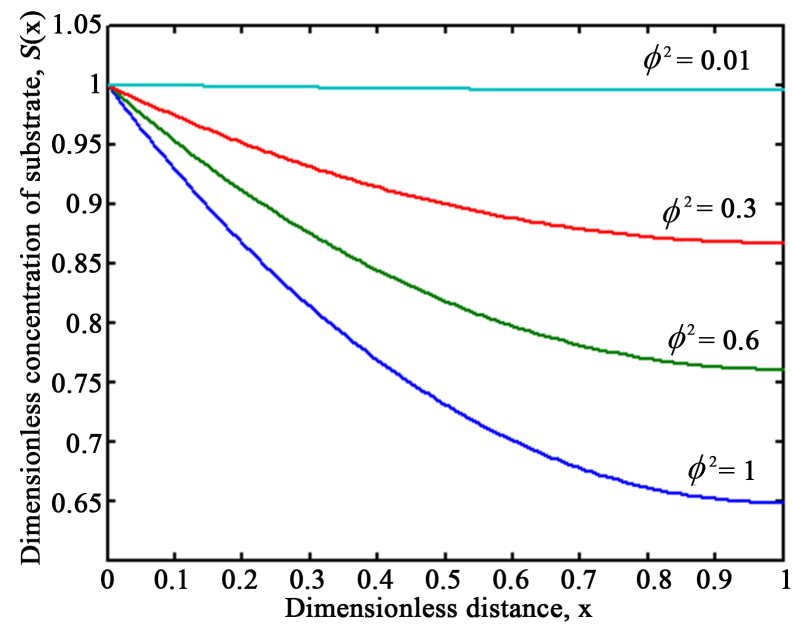

(a)

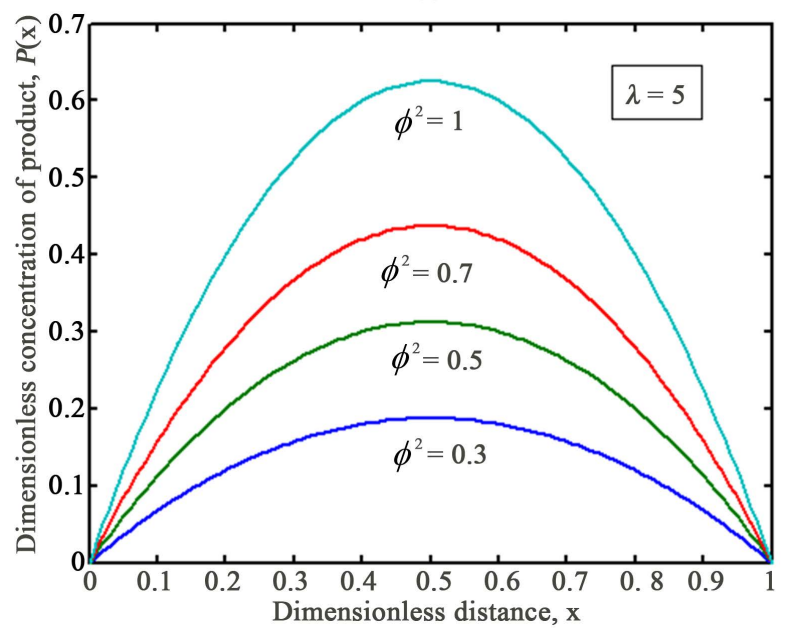

(c)

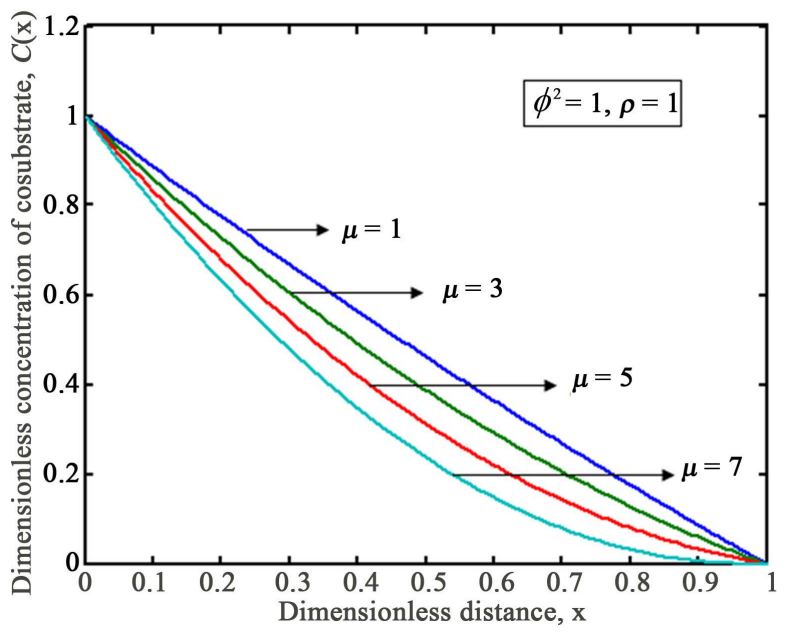

(e)

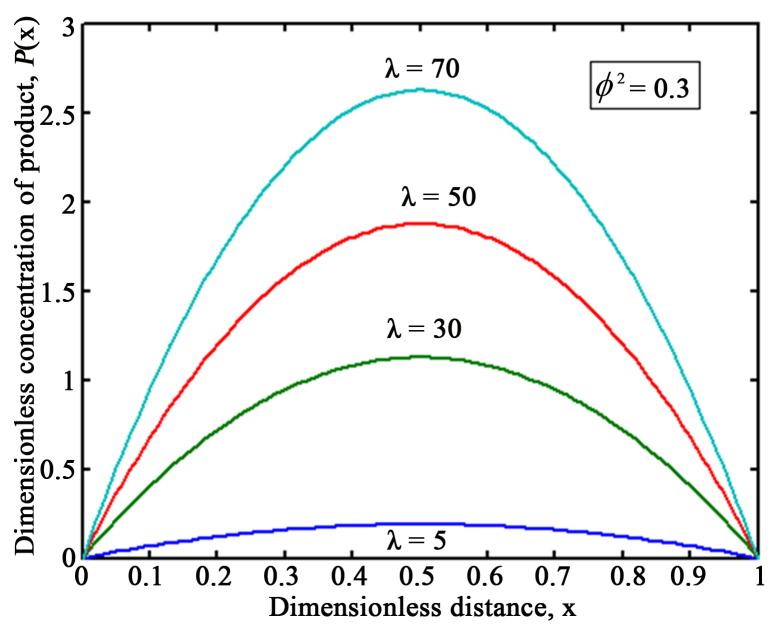

(b)

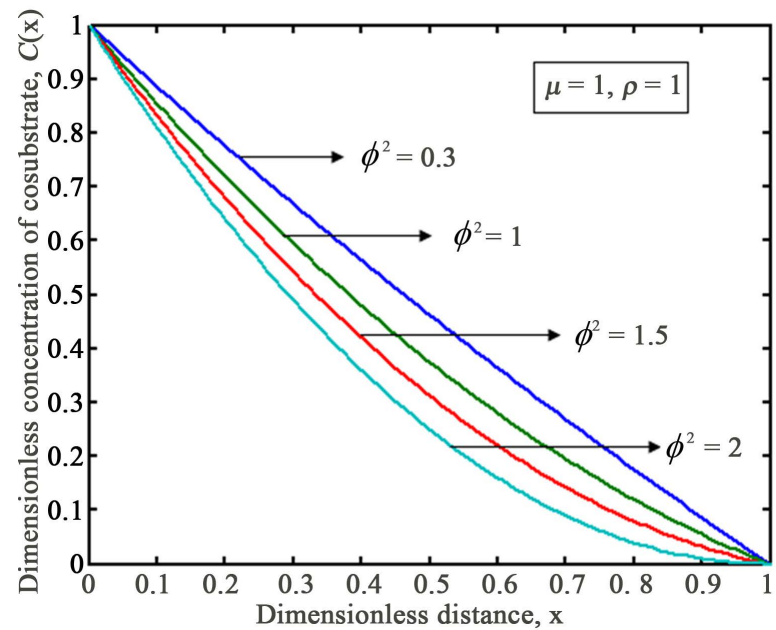

(d)

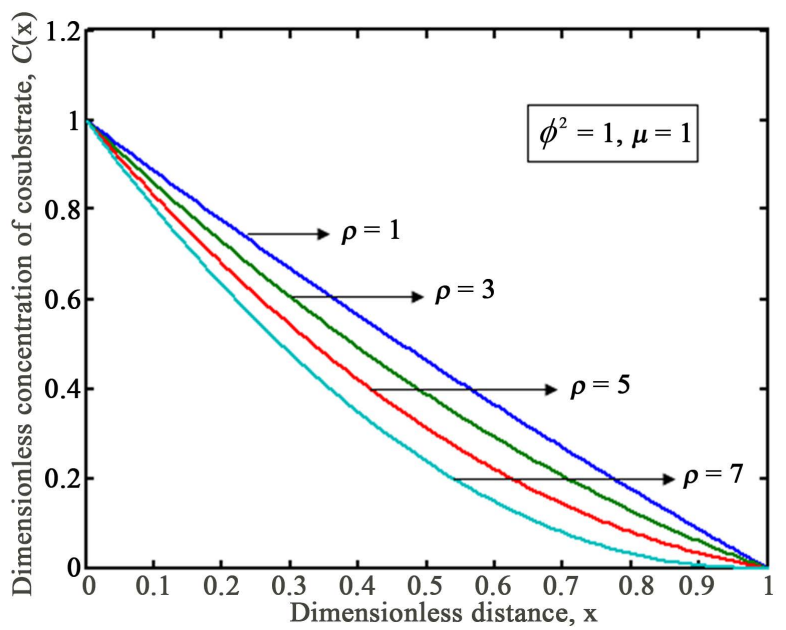

(f)

Figure 1. (a)-(f) Plot of dimensionless concentrations of the substrate $S(x)$, product $P(x)$ and co-substrate $C(x)$ versus dimensionless distance $x$ of the first-order kinetics are calculated using Equations (18), (19) and (20), respectively for different values of the Thiele modulus $\phi^{2}$, Diffusion coefficient of $\lambda$, Reaction rate constant for co-substrate $\mu$, and Diffusion coefficient of co-substrate $\rho$. 


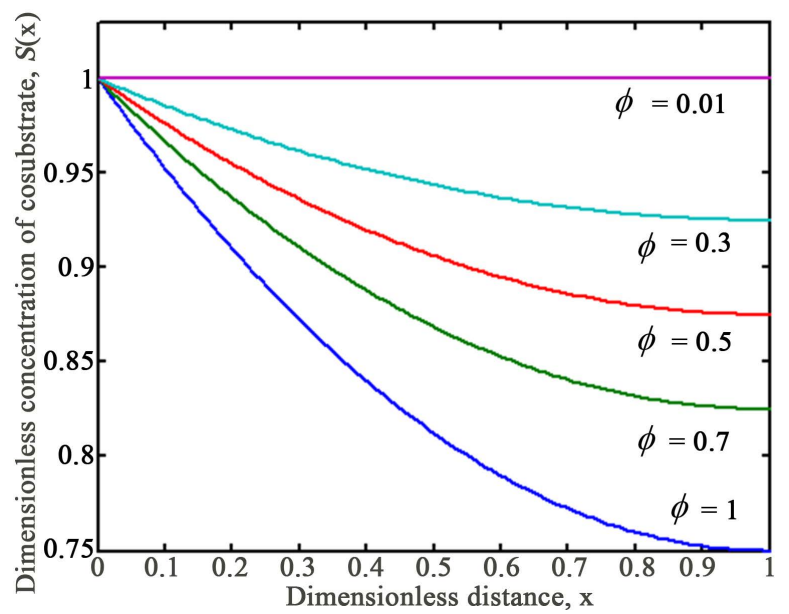

(a)

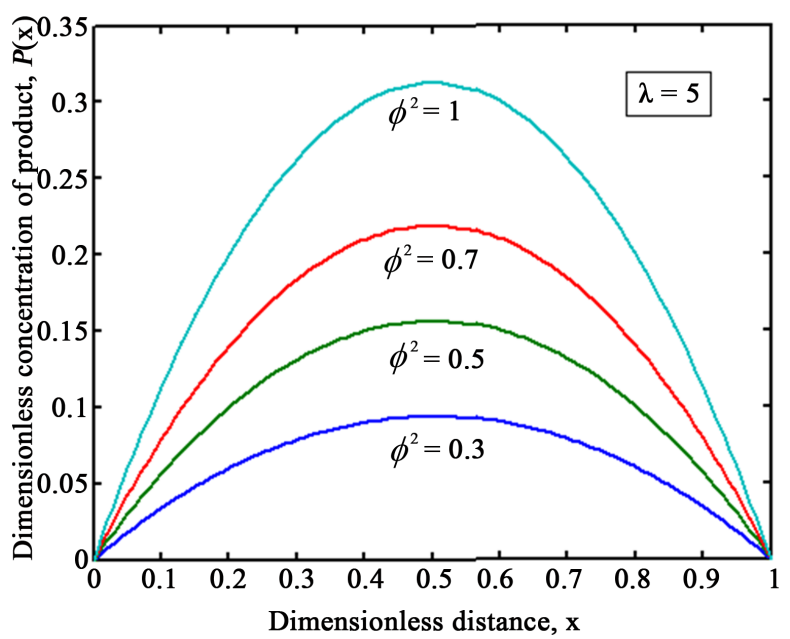

(c)

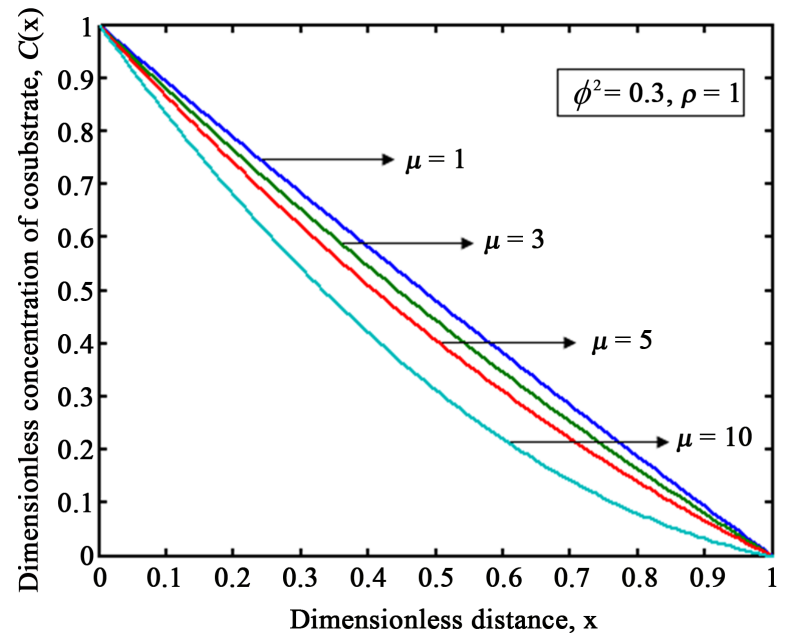

(e)

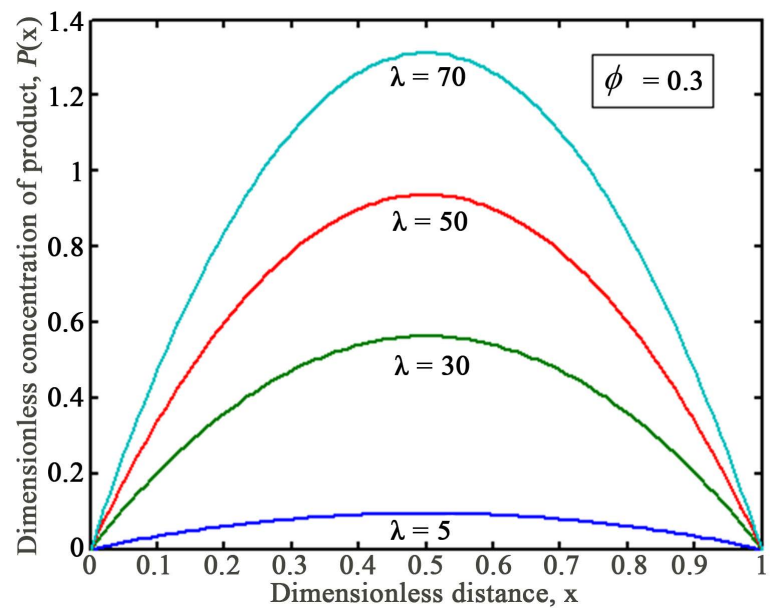

(b)

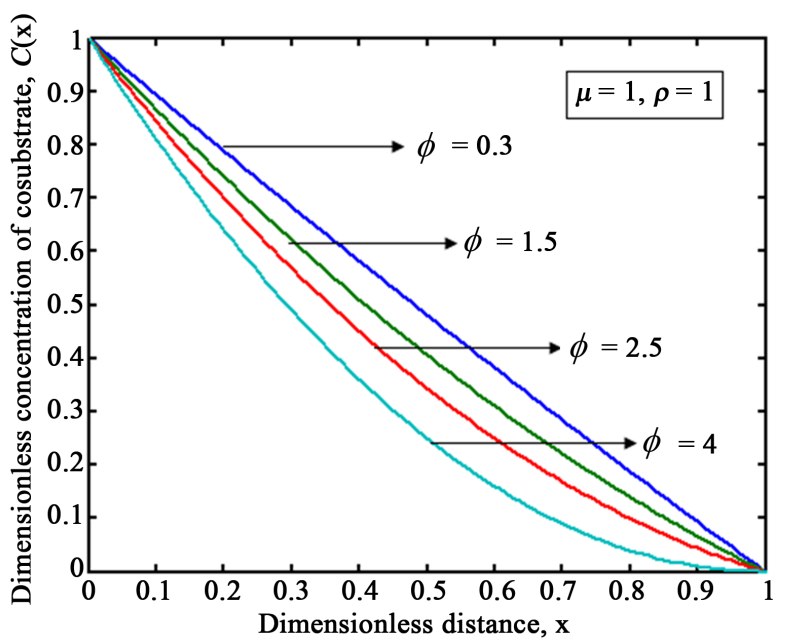

(d)

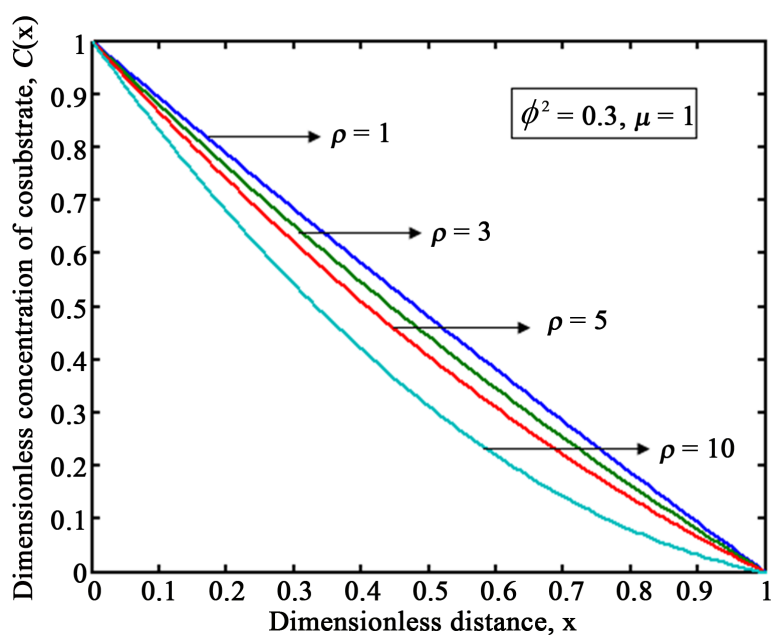

(f)

Figure 2. Plot of dimensionless concentrations of the substrate $S(x)$, product $P(x)$ and co-substrate $C(x)$ versus dimensionless distance $x$ of the Michalies menten kinetics are calculated using Equations (24), (25) and (26), respectively for different values of the Thiele modulus $\phi^{2}$, Diffusion coefficient of $\lambda$, Reaction rate constant for co-substrate $\mu$, and Diffusion coefficient of co-substrate $\rho$. 


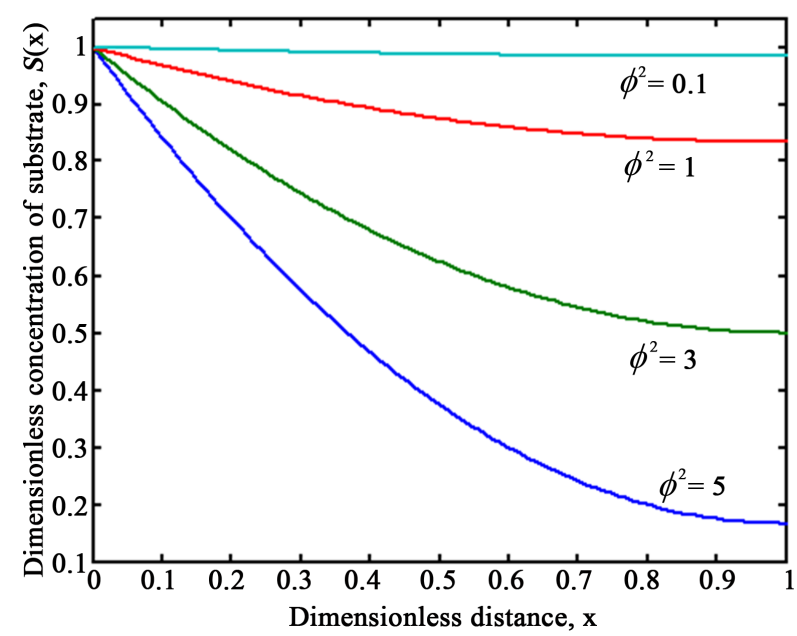

(a)

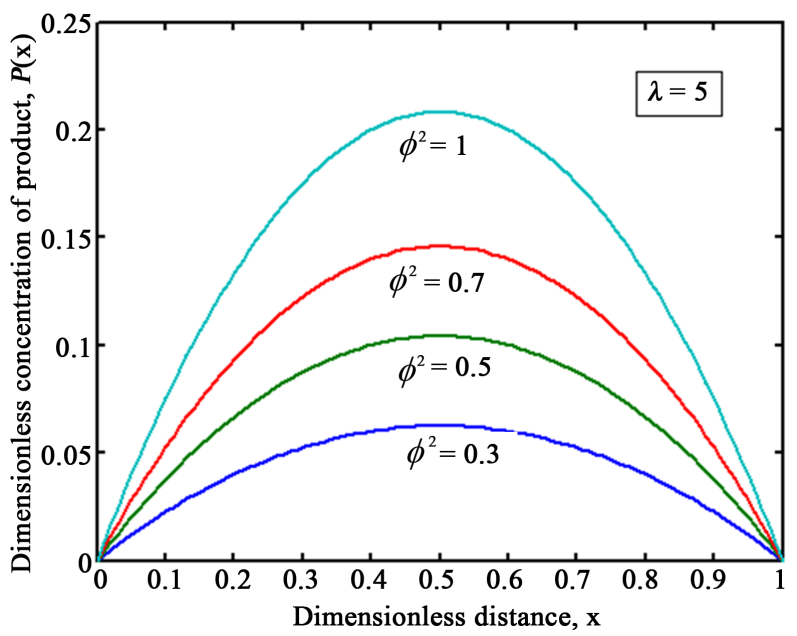

(c)

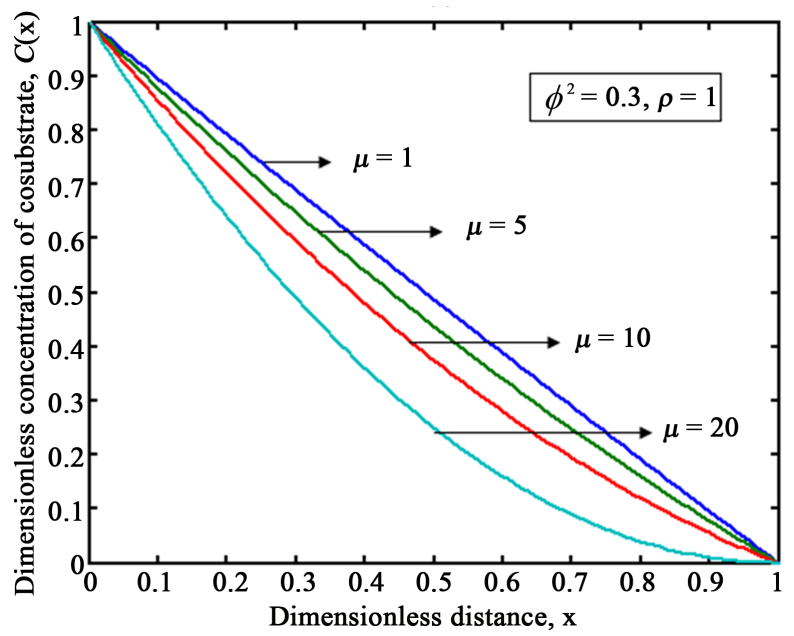

(e)

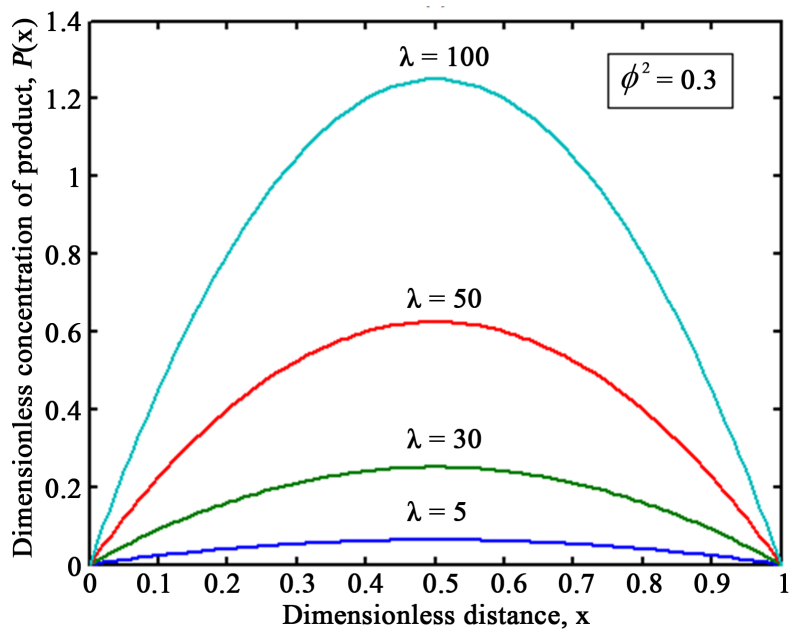

(b)

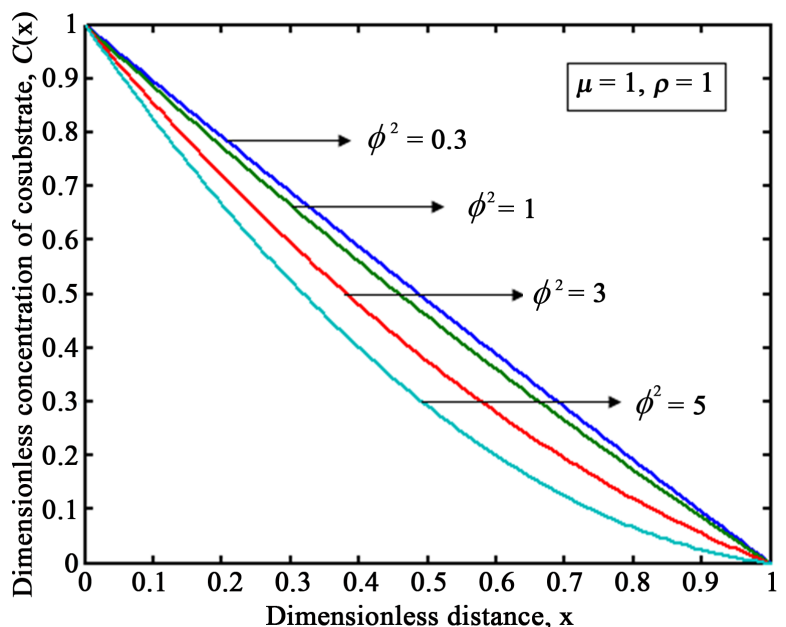

(d)

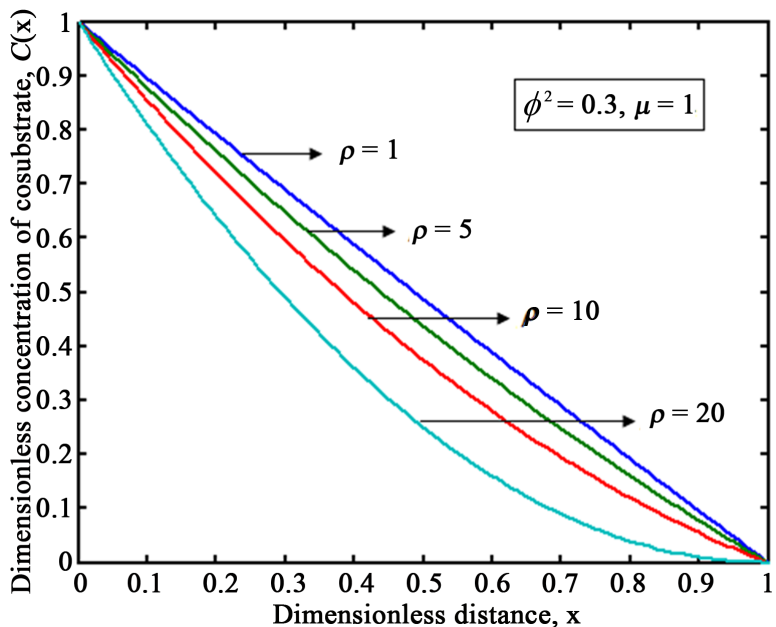

(f)

Figure 3. (a)-(f) Plot of dimensionless concentrations of the substrate $S(x)$, product $P(x)$ and co-substrate $C(x)$ versus dimensionless distance $x$ of the Michalies menten kinetics are calculated using Equations (30), (31) and (32), respectively for different values of the Thiele modulus $\phi^{2}$, Diffusion coefficient of $\lambda$, Reaction rate constant for co-substrate $\mu$, and Diffusion coefficient of co-substrate $\rho$. 


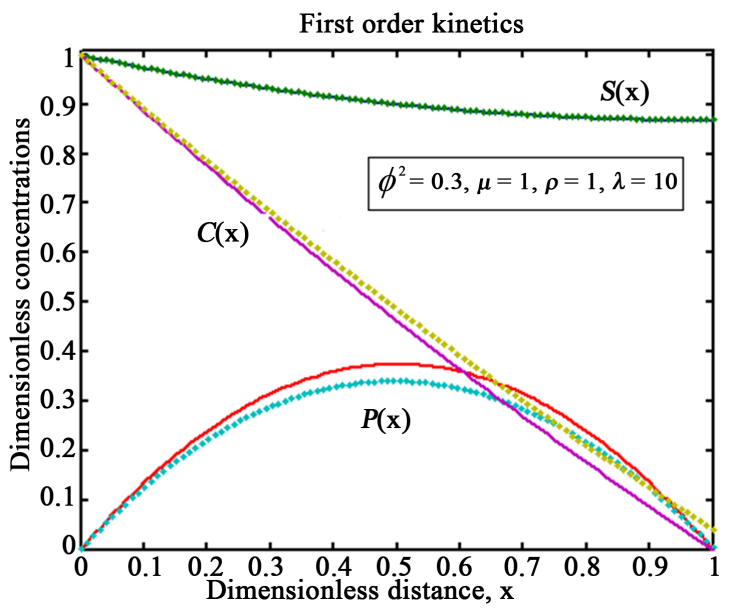

(a)

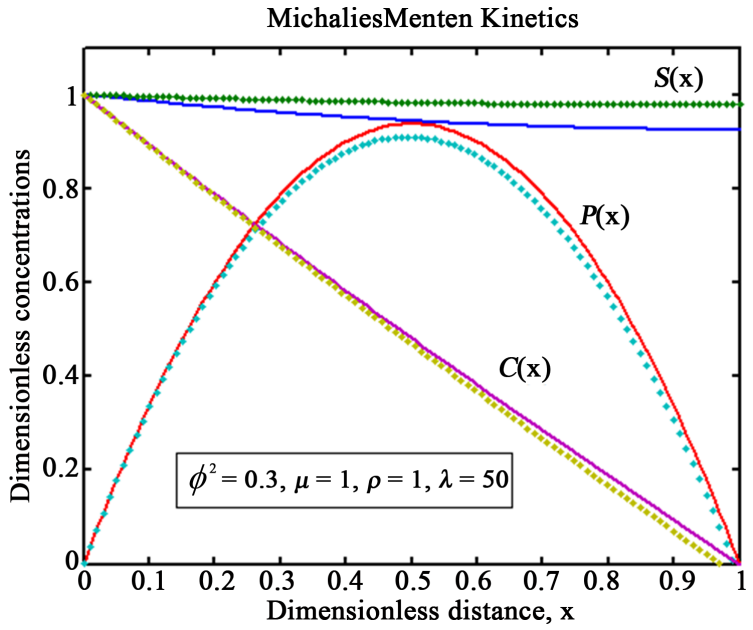

(b)

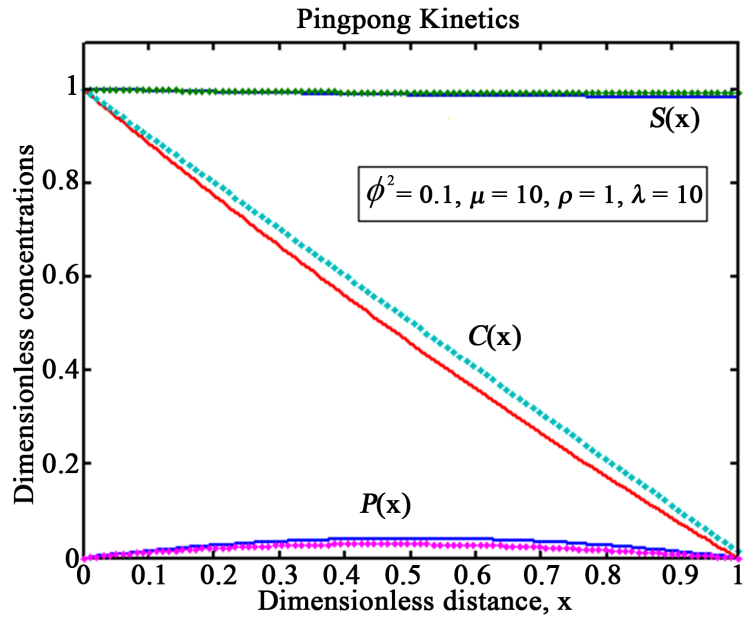

(c)

Figure 4. Concentration of substrate $S(x)$, Product $P(x)$ and co-substrate $C(x)$ versus dimensionless distance $x$ of first order, Michalies-Menten and ping-pong kineticare represented using Equations (18)-(20) for substrate and Equations (24)-(26) for product and Equations (30)-(32) for co-substrate, respectively for some fixed values of parameters. 


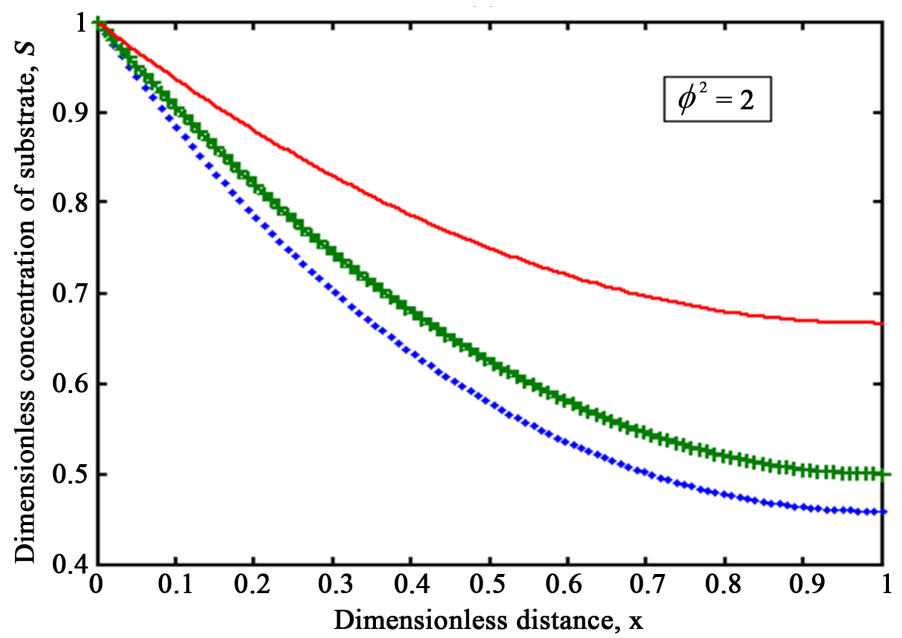

(a)

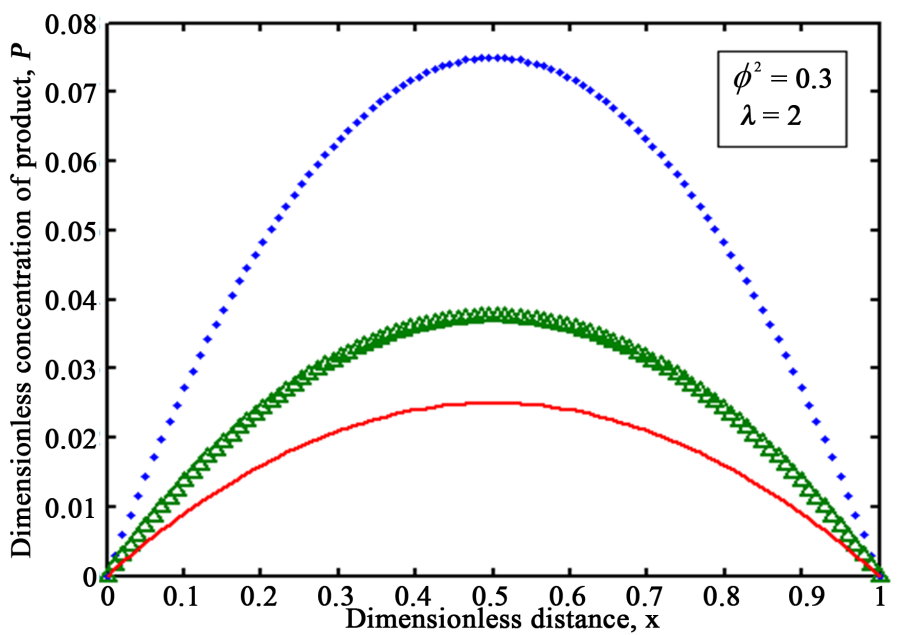

(b)

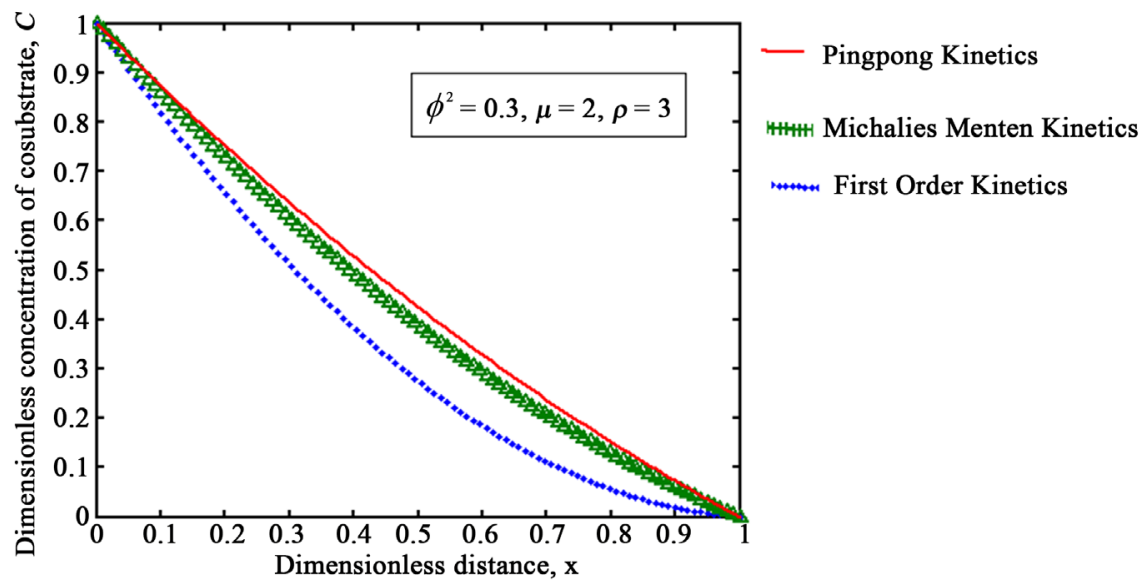

(c)

Figure 5. Concentration of substrate $S(x)$, Product $P(x)$ and co-substrate $C(x)$ versus dimensionless distance $x$ of first order, Michalies-Menten and ping-pong kinetic are represented using Equations (18), (24) and (30) for substrate and Equations (19), (25) and (31) for product and Equations (20), (26) and (32) for co-substrate, respectively for some fixed values of parameters. 


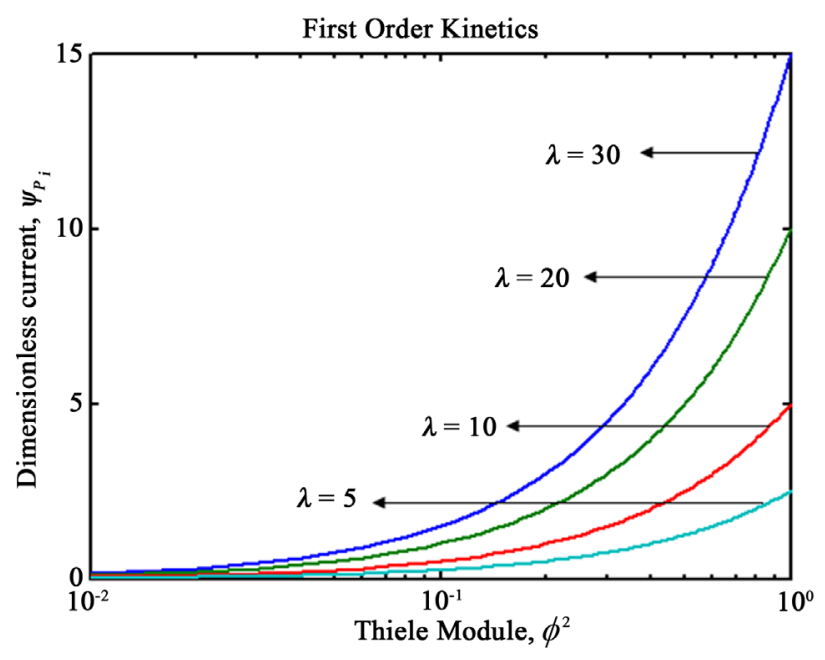

(a)

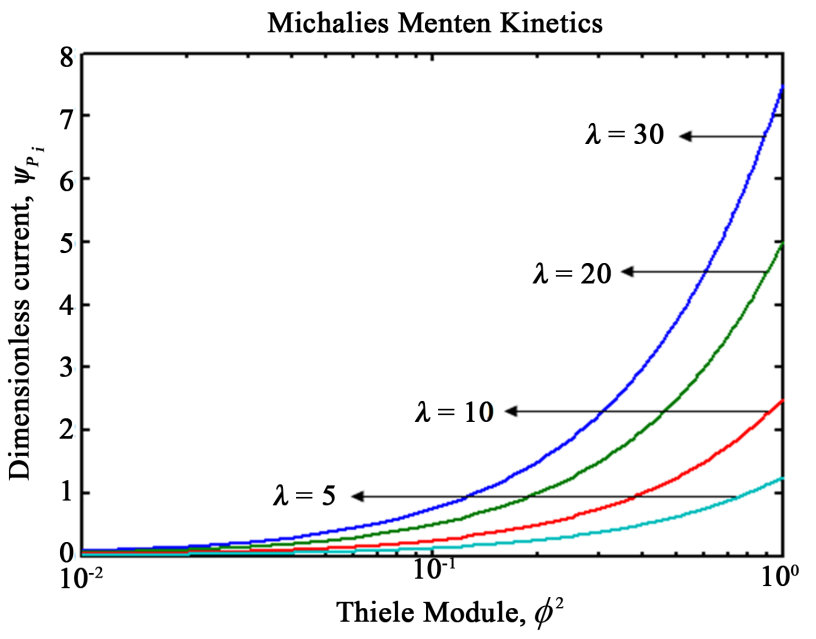

(b)

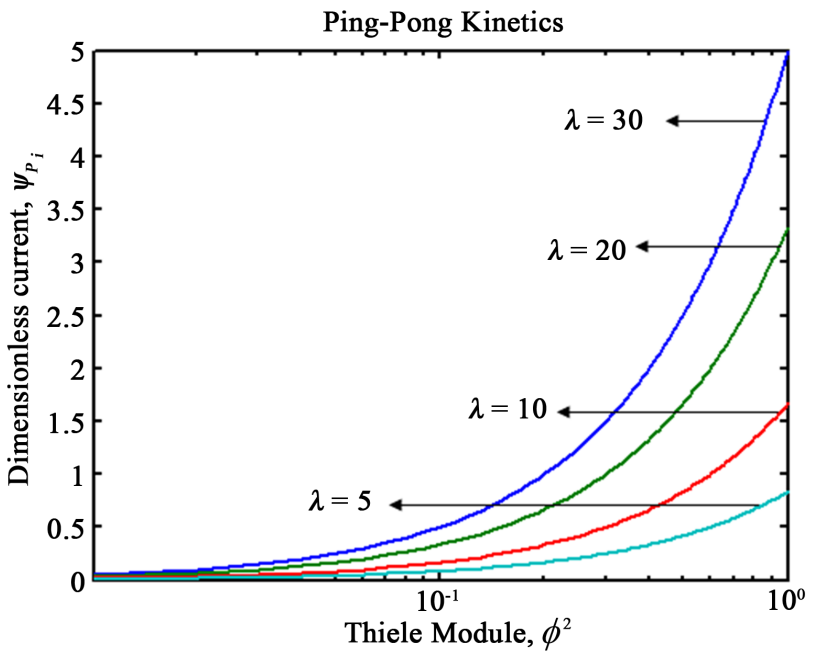

(c)

Figure 6. Generalised graph of the dimensionless current for product $\psi_{P_{i}}$ versus Thiele module $\phi^{2}$ of first order, Michalies-Menten and ping-pong kineticare represented using Equations (22), (28) and (34), respectively for some fixed values of parameters. 
First Order Kinetics

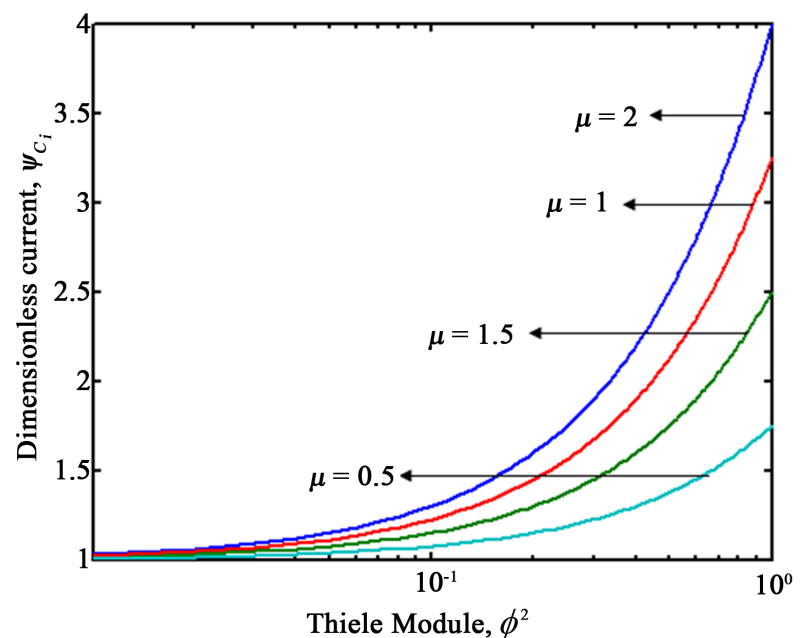

(a)

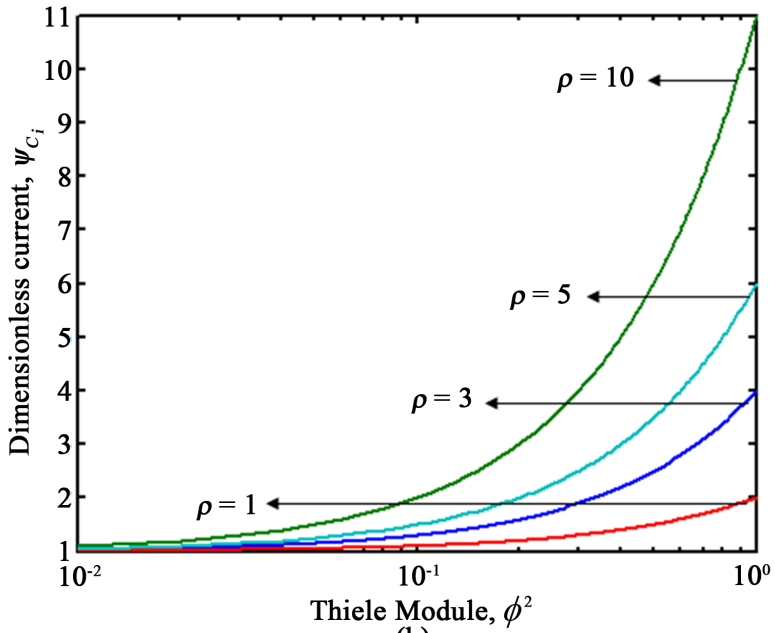

(b)

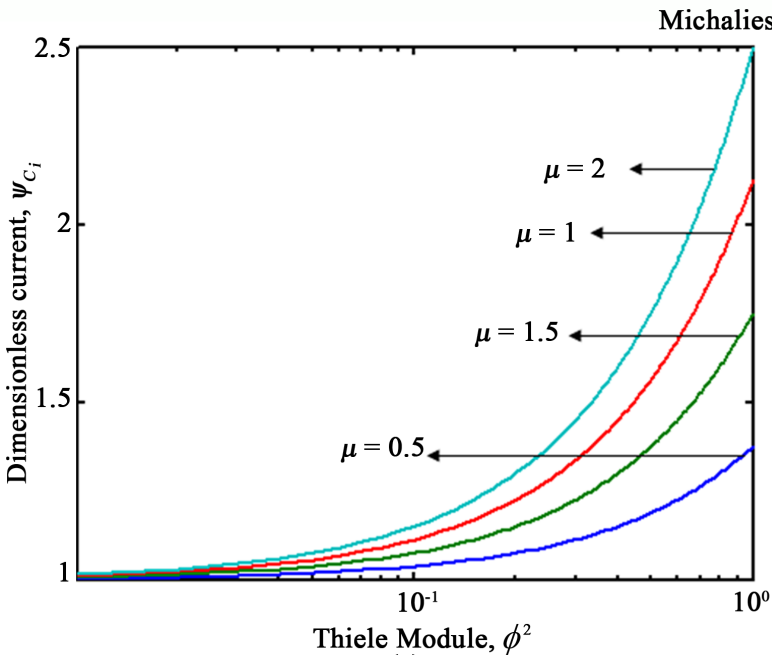

(c)

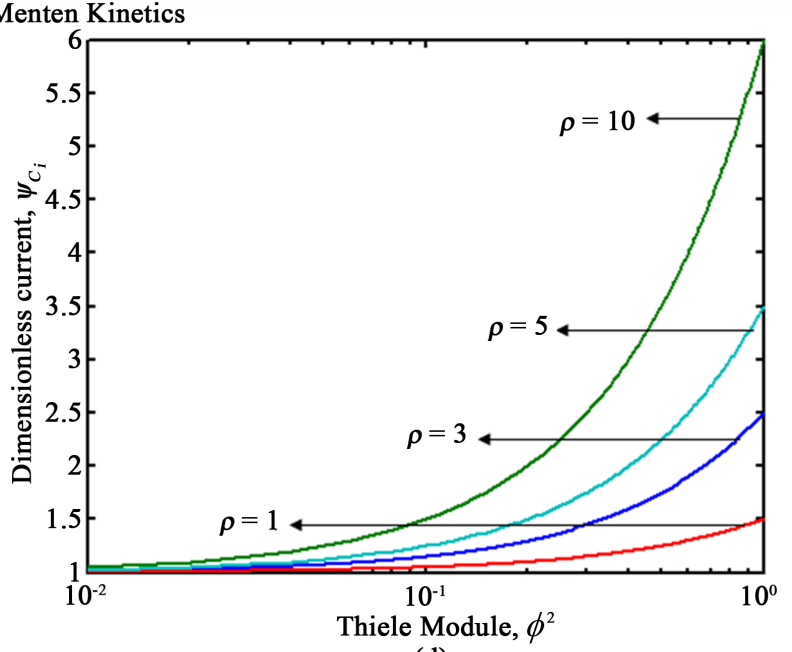

(d)

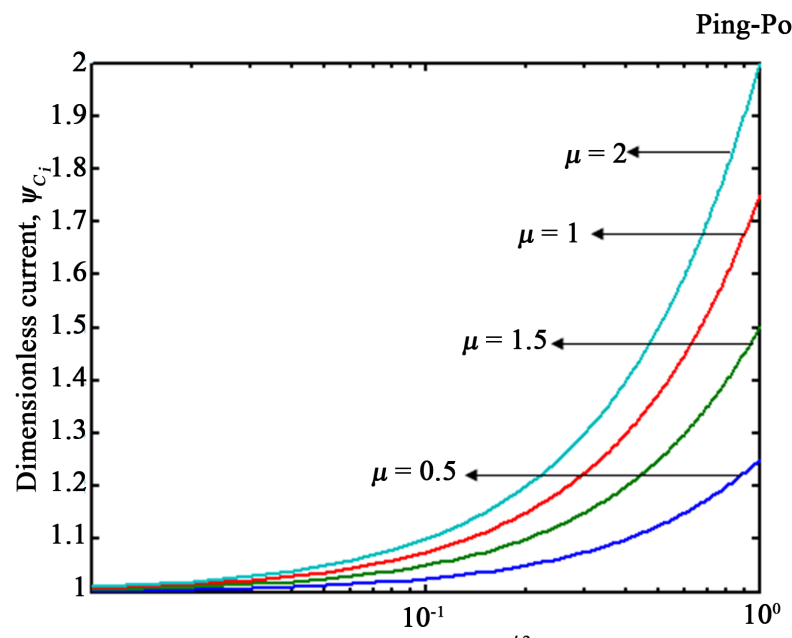

Thiele Module, $\phi^{2}$

(e)

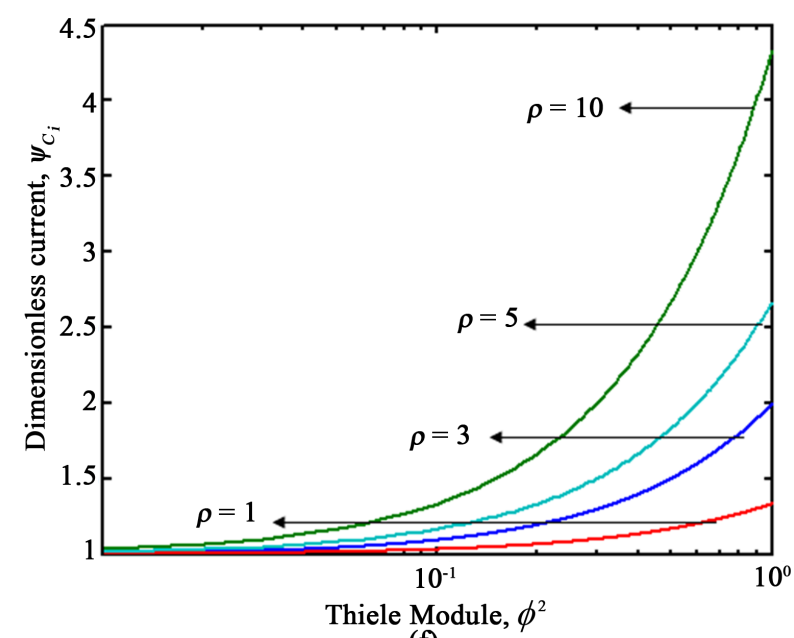

(f)

Figure 7. Generalised graph of the dimensionless current for co-substrate product $\psi_{C_{i}}$ versus Thiele module $\phi^{2}$ of first order, Michalies-Menten and ping-pong kineticare represented using Equations (23), (29) and (34), respectively for some fixed values of parameters. 
of the procedure to other systems nonlinear equation in various type of biosensor seems to be possible.

\section{References}

[1] Thevenot, D.R., Toth, K., Durst, R.A. and Wilson, G.S. (2001) Electrochemical Biosensors: Recommended Definitions and Classification. Biosensors and Bioelectronics, 16, 121-131.

[2] Newman, J.D., Tigwell, L.J., Turner, A.P.F. and Warner, P.J. (2004) Biosensors-A Clearer View. Cranfield University Publication.

[3] Mascini, M. and Tombelli, S. (2008) Biosensors for Biomarkers in Medical Diagnostics. Biomarkers, 13, 637-657. https://doi.org/10.1080/13547500802645905

[4] Zhang, Y., Yang, D., Weng, L. and Wang, L. (2013) Early Lung Cancer Diagnosis by Biosensors. International Journal of Molecular Sciences, 14, 15479-15509. https://doi.org/10.3390/ijms140815479

[5] Turner, A.P. (2013) Biosensors: Sense and Sensibility. Chemical Society Review, 42, 3184-3196.

[6] Rangelova, V., Katsarova, P. and Iliev, K.J. (2007) Influence of Parameters over Biosensors Response in Dynamic Mode at Different Enzyme Kinetic. Annals of the Faculty of Engineering Hunedoara-Journal of Engineering, 5, 105-112.

[7] Rangelova, V. (2006) Modeling Amperometric Biosensor with Cyclic Reaction. Annals of the Faculty of Engineering Hunedoara-Journal of Engineering, 5, 116-122.

[8] Rangelova, V., Pandelova, A. and Stoiyanov, N. (2011) Inhibitor Multienzyme Biosensor System in Dynamic Mode-Phosphate Measurement. Annals of the Faculty of Engineering Hunedoara-Journal of Engineering, 9, 83-86.

[9] Tothill, I.E. (2001) Biosensors Developments and Potential Applications in the Agricultural Diagnosis Sector. Computers and Electronics in Agriculture, 30, 205218.

[10] Mishra, S., Saadat, D., Kwon, O., Lee, Y., Choi, W.S., Kim, J.H. and Yeo, W.H. (2016) Recent Advances in Salivary Cancer Diagnostics Enabled by Biosensors and Bioelectronics. Biosensors and Bioelectronics, 81, 181-197.

[11] Cortina, M.E., Melli, L.J., Roberti, M., Mass, M., Longinotti, G., Tropea, S., Lloret, P., Serantes, D.A.R., Salomón, F., Lloret, M., Caillava, A.J., Restuccia, S., Altcheh, J., Buscaglia, C.A., Malatto, L., Ugalde, J.E., Fraigi, L., Moina, C., Ybarra, G., Ciocchini, A.E. and Comerci, D.J. (2016) Electrochemical Magnetic Microbeads-Based Biosensor for Point-of-Care Sero-Diagnosis of Infectious Diseases. Biosensors and Bioelectronics, 80, 24-33.

[12] Lawal, A.T. (2016) Synthesis and Utilization of Carbon Nanotubes for Fabrication of Electrochemical Biosensors. Materials Research Bulletin, 73, 308-350.

[13] Gruhl, F.J., Rapp, B.E. and Länge, K. (2013) Biosensors for Diagnostic Applications. In: Seitz, H. and Schumacher, S., Eds., Molecular Diagnostics. Advances in Biochemical Engineering/Biotechnology, Vol. 133, Springer, Berlin, Heidelberg, 115148. https://doi.org/10.1007/10_2011_130

[14] Baronas, R., Ivanauskas, F. and Kulys, J. (1999) Modelling a Biosensor Based on the Heterogeneous Microreactor. Journal of Mathematical Chemistry, 25, 245-252. https://doi.org/10.1023/A:1019192618843

[15] Ames, W.F. (1977) Numerical Methods for Partial Differential Equations. 2nd Edition, Academic Press, New York.

[16] Meena, A. and Rajendran, L. (2010) Mathematicalmodeling of Amperometric and 
Potentiometric Biosensors and System of Nonlinear Equations-Homotopy Perturbation Approach. Journal of Electroanalytical Chemistry, 644, 50-59.

[17] Loghambal, S. and Rajendran, L. (2011) Mathematical Modeling in Amperometric Oxidase Enzyme-Membrane Electrodes. Journal of Membrane Science, 373, 20-28.

[18] Manimozhi, P., Subbiah, A. and Rajendran, L. (2010) Solution of Steady-State Substrate Concentration in the Action of Biosensor Response at Mixed Enzyme Kinetics. Sensors and Actuators B: Chemical, 147, 290-297.

[19] Venugopal, K., Eswari, A. and Rajendran, L. (2011) Mathematical Model for Steady State Current at PPO-Modified Micro-Cylinder Biosensors. Journal of Biomedical Science and Engineering, 4, 631-641. https://doi.org/10.4236/jbise.2011.49079

[20] Kirthiga, O.M. and Rajendran, L. (2015) Approximate Analytical Solution for Non-Linear Reaction Diffusion Equations in a Mono-Enzymatic Biosensor Involving Michaelis-Menten Kinetics. Journal of Electroanalytical Chemistry, 751, 119 127.

[21] Saravanakumara, K., Rajendrana, L. and Sangaranarayananb, M.V. (2015) Current-Potential Response and Concentration Profiles of Redoxpolymer-Mediated Enzyme Catalysis in Biofuel Cells-Estimation of Michaelis-Menten Constants. Chemical Physics Letters, 621, 117-123.

[22] Katzarova, P., Rangelova, V. and Kuneva, S. (2006) Two Parameters Diagnostic of Biosensor Transducers. Biotechnology \& Biotechnological Equipment, 20, 190-194. https://doi.org/10.1080/13102818.2006.10817331

[23] Öziş, T. and Yildirim, A. (2007) A Comparative Study of He’s Homotopy Perturbation Method for Determining Frequency-Amplitude Relation of a Nonlinear Oscillator with Discontinuities. International Journal of Nonlinear Sciences and Numerical Simulation, 8, 243-248. https://doi.org/10.1515/IJNSNS.2007.8.2.243

[24] Mousa, M.M. and Ragab, S.F. (2008) Application of the Homotopy Perturbation Method to Linear and Nonlinear Schrödinger Equations. Zeitschrift fur Naturforschung, 63, 140-144.

[25] He, J.H. (1999) Homotopy Perturbation Technique. Computer Methods in Applied Mechanics and Engineering, 178, 257-262.

[26] Rajendran, L. and Anitha, S. (2013) Reply to "Comments on Analytical Solution of Amperometric Enzymatic Reactions Based on HPM". Electrochimica Acta, 102, 474-476.

[27] Meena, V., Indira, K., Kumar, S. and Rajendran, L. (2014) A New Mathematical Model for Effectiveness Factors in Biofilm under Toxic Conditions. Alexandria Engineering Journal, 53, 917-928.

[28] Meena, A. and Rajendran, L. (2010) Mathematical Modeling of Amperometric and Potentiometric Biosensors and System of Nonlinear Equations-Homotopy Perturbation Approach. Journal of Electroanalytical Chemistry, 644, 50-59. 


\section{Appendix A}

Approximate analytical solutions for Equations (8)-(10) (Michaelis-Menten kinetic) using HPM:

In order to solve Equation (8-10) by means of the new HPM, first the Zeroth order deformation equation is constructed.

$$
\begin{aligned}
& (1-p) \frac{\mathrm{d}^{2} S}{\mathrm{~d} x^{2}}=p\left\{\frac{\mathrm{d}^{2} S}{\mathrm{~d} x^{2}}-\frac{\phi^{2} S}{1+S}\right\} \\
& (1-p) \frac{\mathrm{d}^{2} P}{\mathrm{~d} x^{2}}=p\left\{\frac{\mathrm{d}^{2} P}{\mathrm{~d} x^{2}}-\frac{\phi^{2} S}{1+S}\right\} \\
& (1-p) \frac{\mathrm{d}^{2} C}{\mathrm{~d} x^{2}}=p\left\{\frac{\mathrm{d}^{2} C}{\mathrm{~d} x^{2}}-\frac{\phi^{2} S}{1+S}\right\}
\end{aligned}
$$

The approximate solutions of Equations (A1), (A2) and (A3) are as follows

$$
\begin{aligned}
& S=S_{0}+p S_{1}+p^{2} S_{2}+\cdots \\
& P=P_{0}+p P_{1}+p^{2} P_{2}+\cdots \\
& C=C_{0}+p C_{1}+p^{2} C_{2}+\cdots
\end{aligned}
$$

Substituting (A4) in Equation (A1) and equating the like powers of $p$, we get

$$
\begin{gathered}
p^{0}: \frac{\mathrm{d}^{2} S_{0}}{\mathrm{~d} x^{2}}=0 \\
p^{1}: \frac{\mathrm{d}^{2} S_{1}}{\mathrm{~d} x^{2}}=\frac{-\lambda \phi^{2} S_{0}}{1+S_{0}}
\end{gathered}
$$

Substituting (A4) in Equation (A2) and equating the like powers of $p$, we get

$$
\begin{gathered}
p^{0}: \frac{\mathrm{d}^{2} P_{0}}{\mathrm{~d} x^{2}}=0 \\
p^{1}: \frac{\mathrm{d}^{2} P_{1}}{\mathrm{~d} x^{2}}=\frac{\lambda \phi^{2} S_{0}}{1+S_{0}}
\end{gathered}
$$

Substituting (A4) in Equation (A3) and equating the like powers of $p$, we get

$$
\begin{gathered}
p^{0}: \frac{\mathrm{d}^{2} C_{0}}{\mathrm{~d} x^{2}}=0 \\
p^{1}: \frac{\mathrm{d}^{2} P_{1}}{\mathrm{~d} x^{2}}=\frac{-\mu \rho \phi^{2} S_{0}}{1+S_{0}}
\end{gathered}
$$

The boundary conditions in Equation (14) becomes

$$
\begin{aligned}
& S_{0}(x=0)=s_{0}, \frac{\mathrm{d} S_{0}}{\mathrm{~d} x}(x=l), P_{0}(x=0)=0, P_{0}(x=l)=0 \\
& \text { and } C_{0}(x=0)=c_{0}, C_{0}(x=l)=0
\end{aligned}
$$

and

$$
\begin{aligned}
& S_{i}(x=0)=0, \frac{\mathrm{d} S_{i}}{\mathrm{~d} x}(x=l), P_{i}(x=0)=0, P_{i}(x=l)=0 \\
& \text { and } C_{i}(x=0)=0, C_{i}(x=l)=0 \text { for all } i=1,2,3, \cdots
\end{aligned}
$$


Now by applying the boundary conditions (A11) in (A5), (A7) and (A9), we get

$$
\begin{gathered}
S_{0}(x)=S_{0} \\
P_{0}(x)=0 \\
C_{0}(x)=c_{0}(1-x)
\end{gathered}
$$

Substituting the values of $S_{0}, P_{0}$ and $C_{0}$ in Equation (A6), (A8) and (A10), and respectively by solving the equations using the boundary conditions (A12), the following results are obtained:

$$
\begin{gathered}
\frac{S_{1}(x)}{S_{0}}=\frac{\phi^{2}}{1+S_{0}}\left(\frac{x^{2}}{2}-x\right) \\
P_{1}(x)=\frac{-\lambda \phi^{2} S_{0}}{2\left(1+S_{0}\right)}\left(x^{2}-x\right) \\
C_{1}(x)=\frac{\mu \rho \phi^{2} S_{0}}{2\left(1+S_{0}\right)}\left(x^{2}-x\right)
\end{gathered}
$$

Adding Equations (A13) and (A16), we get Equation (24) in the text. Similarly, Equation (25) and Equation (26) are got in the text.

\section{Appendix B}

Approximate analytical solutions for Equations (11-13) (ping-pong kinetic) using HPM:

In order to solve Equations (11-13) by means of the new HPM, first the Zeroth order deformation equation is constructed.

$$
\begin{aligned}
& (1-p) \frac{\mathrm{d}^{2} S}{\mathrm{~d} x^{2}}=p\left\{\frac{\mathrm{d}^{2} S}{\mathrm{~d} x^{2}}-\frac{\phi^{2}}{1+1 / S+1 / C}\right\} \\
& (1-p) \frac{\mathrm{d}^{2} C}{\mathrm{~d} x^{2}}=p\left\{\frac{\mathrm{d}^{2} C}{\mathrm{~d} x^{2}}-\frac{\phi^{2}}{1+1 / S+1 / C}\right\} \\
& (1-p) \frac{\mathrm{d}^{2} P}{\mathrm{~d} x^{2}}=p\left\{\frac{\mathrm{d}^{2} P}{\mathrm{~d} x^{2}}+\frac{\phi^{2}}{1+1 / S+1 / C}\right\}
\end{aligned}
$$

The approximate solutions of Equations (B1), (B2) and (B3) are as follows

$$
\begin{aligned}
& S=S_{0}+p S_{1}+p^{2} S_{2}+\cdots \\
& P=P_{0}+p P_{1}+p^{2} P_{2}+\cdots \\
& C=C_{0}+p C_{1}+p^{2} C_{2}+\cdots
\end{aligned}
$$

Substituting (B4) in Equations (B1) and equating the like powers of $p$, we get

$$
\begin{gathered}
p^{0}: \frac{\mathrm{d}^{2} S_{0}}{\mathrm{~d} x^{2}}=0 \\
p^{1}: \frac{\mathrm{d}^{2} S_{1}}{\mathrm{~d} x^{2}}=\frac{\phi^{2}}{1+1 / s_{0}+1 / c_{0}}
\end{gathered}
$$


Substituting (B4) in Equation (B2) and equating the like powers of $p$, we get

$$
\begin{gathered}
p^{0}: \frac{\mathrm{d}^{2} P_{0}}{\mathrm{~d} x^{2}}=0 \\
p^{1}: \frac{\mathrm{d}^{2} P_{1}}{\mathrm{~d} x^{2}}=\frac{-\lambda \phi^{2}}{1+1 / s_{0}+1 / c_{0}}
\end{gathered}
$$

Substituting (B4) in Equation (B3) and equating the like powers of $p$, we get

$$
\begin{gathered}
p^{0}: \frac{\mathrm{d}^{2} C_{0}}{\mathrm{~d} x^{2}}=0 \\
p^{1}: \frac{\mathrm{d}^{2} C_{1}}{\mathrm{~d} x^{2}}=\frac{\mu \rho \phi^{2}}{1+1 / s_{0}+1 / c_{0}}
\end{gathered}
$$

The boundary conditions in Equation (14) becomes

$$
\begin{aligned}
& S_{0}(x=0)=s_{0}, \frac{\mathrm{d} S_{0}}{\mathrm{~d} x}(x=l), P_{0}(x=0)=0, P_{0}(x=l)=0 \\
& \text { and } C_{0}(x=0)=c_{0}, C_{0}(x=l)=0
\end{aligned}
$$

and

$$
\begin{aligned}
& S_{i}(x=0)=0, \frac{\mathrm{d} S_{i}}{\mathrm{~d} x}(x=l), P_{i}(x=0)=0, P_{i}(x=l)=0 \\
& \text { and } C_{i}(x=0)=0, C_{i}(x=l)=0 \text { for all } i=1,2,3, \cdots
\end{aligned}
$$

Now by applying the boundary conditions (B11) in (B5), (B7) and (B9), we get

$$
\begin{gathered}
S_{0}(x)=s_{0} \\
P_{0}(x)=0 \\
C_{0}(x)=c_{0}(1-x)
\end{gathered}
$$

Substituting the values of $S_{0}, P_{0}$ and $C_{0}$ in Equation (B6), (B8) and (B10), and solving the equations using the boundary conditions (B12), the following results are obtained:

$$
\begin{gathered}
S_{1}(x)=\frac{\phi^{2}}{1+1 / s_{0}+1 / c_{0}}\left(\frac{x^{2}}{2}-x\right) \\
P_{1}(x)=\frac{-\phi^{2} \lambda}{2\left(1+1 / s_{0}+1 / c_{0}\right)}\left(x^{2}-x\right) \\
C_{1}(x)=\frac{-\phi^{2} \mu \rho}{2\left(1+1 / s_{0}+1 / c_{0}\right)}\left(x^{2}-x\right)
\end{gathered}
$$

Adding Equations (B13) and (B16), we get Equation (30) in the text. Similarly, Equation (31) and Equation (32) are got in the text.

\section{Appendix C}

Scilab/Matlab program for the numerical solution of the system of nonlinear Equations (5-13). 
function pdex4

$\mathrm{m}=0$;

$\mathrm{x}=$ linspace $(0,1)$

$\mathrm{t}=$ linspace $(0,100000)$;

sol=pdepe $(\mathrm{m}, @ p d e x 4 p d e, @ p d e x 4 i c, @ p d e x 4 b c, x, t)$;

$\mathrm{u} 1=\operatorname{sol}(:,:, 1)$;

$\mathrm{u} 2=\operatorname{sol}(:,:, 2)$;

u3 = sol(:,:,3);

figure

$\operatorname{plot}(\mathrm{x}, \mathrm{u} 1(\mathrm{end}, \mathrm{:}))$

title('u1 $(\mathrm{x}, \mathrm{t})$ ')

xlabel('Distance $\mathrm{x}$ ')

ylabel('ul $(\mathrm{x}, 2)$ ')

$\%$

figure

$\operatorname{plot}(\mathrm{x}, \mathrm{u} 2(\mathrm{end}, \mathrm{:}))$

title('u2(x,t)')

xlabel('Distance $\left.\mathrm{x}^{\prime}\right)$

ylabel('u2(x,2)')

$\%$

figure

$\operatorname{plot}(\mathrm{x}, \mathrm{u} 3(\mathrm{end}, \mathrm{:}))$

title('u3(x,t)')

xlabel('Distance $\mathrm{x}$ ')

ylabel('u3(x,2)')

$\%$ -

function $[\mathrm{c}, \mathrm{f}, \mathrm{s}]=\operatorname{pdex} 4 \mathrm{pde}(\mathrm{x}, \mathrm{t}, \mathrm{u}, \mathrm{DuDx})$

$\mathrm{c}=[1 ; 1 ; 1]$;

$\mathrm{f}=[1 ; 1 ; 1] . .^{*} \mathrm{DuDx}$

$\mathrm{l}=0.1 ; \mathrm{mu}=0.5 ; \mathrm{q}=1 ; \mathrm{p}=5$;

$\mathrm{F}=-\mathrm{q}^{\wedge} 2^{*} \mathrm{u}(1)$;

$\mathrm{F} 1=\mathrm{l}^{\star} \mathrm{q}^{\wedge} 2^{\star} \mathrm{u}(1)$;

$\mathrm{F} 2=-\mathrm{mu}^{\star} \mathrm{p}^{\star} \mathrm{q}^{\wedge} 2^{\star} \mathrm{u}(1)$;

$\mathrm{s}=[\mathrm{F} ; \mathrm{F} 1 ; \mathrm{F} 2]$;

$\%$

function $\mathrm{u} 0=\operatorname{pdex} 4 \mathrm{ic}(\mathrm{x})$;

$\mathrm{u} 0=[1 ; 1 ; 1] ;$

$\%$

function [pl,ql,pr,qr] $=\mathrm{pdex} 4 \mathrm{bc}(\mathrm{xl}, \mathrm{ul}, \mathrm{xr}, \mathrm{ur}, \mathrm{t})$

$\mathrm{pl}=[\mathrm{ul}(1)-1 ; \mathrm{ul}(2)-0 ; \mathrm{ul}(3)-1]$;

$\mathrm{ql}=[0 ; 0 ; 0]$;

$\mathrm{pr}=[0 ; \operatorname{ur}(2)-0 ; \operatorname{ur}(3)-0] ;$

$\mathrm{qr}=[1 ; 0 ; 0] ;$ 


\section{Nomenclature}

\section{Symbol}

$A_{1}, A_{2}, A_{3}$ Dimensionless parameters

$[S]$ Concentration of substrate $(\mathrm{mmol})$

$[P]$ Concentration of substrate $(\mathrm{mmol})$

[C] Concentration of substrate (mmol)

$S$ Dimensionless concentration of substrate ( $\mathrm{mmol})$

$P$ Dimensionless concentration of product (mmol)

$C$ Dimensionless concentration of co-substrate ( $\mathrm{mmol}$ )

$s_{0}$ Initial concentration of substrate (mmol)

$p_{0}$ Initial concentration of product ( $\left.\mathrm{mmol}\right)$

$c_{0}$ Initial concentration of co-substrate (mmol)

$K_{i}$ Reaction rate constant ( $\mathrm{mmol}$ )

$D_{i}$ Diffusion coefficient $\left(\mathrm{m}^{2} / \mathrm{s}\right)$

$V_{m}$ Enzymatic rate $(\mathrm{mmol} / \mathrm{s})$

$I_{i}$ Output current

$n$ Number of electrons

$F$ Faraday's number $(\mathrm{C} / \mathrm{mol})$

A Area of the electrode surface $\left(\mathrm{m}^{2}\right)$

l Dimensionless distance

\section{Greek symbols}

$\lambda$ Diffusion coefficient of substrate and product (Dimensionless)

$\mu$ Diffusion coefficient of substrate and co-substrate (Dimensionless)

$\rho$ Reaction rate constant for substrate and co-substrate (Dimensionless)

$\phi^{2}$ Thiele Module (Dimensionless)

$\delta$ dimension distance (m)

$\psi_{i}$ Current (Dimensionless)

Subscripts $i=S, P, C$

$S$ Substrate

$P$ Product

C Co-Substrate 
Submit or recommend next manuscript to SCIRP and we will provide best service for you:

Accepting pre-submission inquiries through Email, Facebook, LinkedIn, Twitter, etc. A wide selection of journals (inclusive of 9 subjects, more than 200 journals)

Providing 24-hour high-quality service

User-friendly online submission system

Fair and swift peer-review system

Efficient typesetting and proofreading procedure

Display of the result of downloads and visits, as well as the number of cited articles Maximum dissemination of your research work

Submit your manuscript at: http://papersubmission.scirp.org/

Or contact ajac@scirp.org 